\title{
Relationships Between Stereotyped Movements and Sensory Processing Disorders in Children With and Without Developmental or Sensory Disorders
}

\author{
Eynat Gal, Murray J. Dyck, Anne Passmore
}

KEY WORDS

- autistic disorder

- developmental disabilities

- hearing disorders

- sensory integrative dysfunction

- sensory processing

- stereotypic movement disorder

- visual disorders
Eynat Gal, OTR, PhD, is Lecturer, Department of Occupational Therapy, University of Haifa, Mount Carmel, Haifa 31905 Israel; eynatgal@gmail.com or egal@univ. haifa.ac.il

Murray J. Dyck, PhD, is Professor of Clinical Psychology, School of Psychology, Griffith University, Gold Coast, Australia.

Anne Passmore, PhD, PGradDip (HIthScEd), BAppSc (OT), is Associate Professor, Center for Research Into Disability and Society, Curtin Health Innovation Research Institute, School of Occupational Therapy and Social Work, Curtin University of Technology, Curtin, Western Australia.
OBJECTIVE. Stereotyped movements (SM) are a defining characteristic of autism but are also present in children with a range of sensory and developmental disorders. We examined whether the severity of sensory processing disorders (SPD) was associated with the severity of SM and whether SPD accounted for betweengroup differences in SM.

METHOD. The Short Sensory Profile and the Stereotyped and Self-Injurious Movements Interview were administered to children with autism, intellectual disability, visual impairment, and hearing impairment and to typically developing children.

RESULTS. SPD predicted the severity of SM in all samples and accounted for differences in SM between the groups. Other differences in the severity of SM were the result of diagnosis and the interaction between diagnosis and an intellectual disability.

CONCLUSION. SPD may be a source of SM, but functional connections between these phenomena will need to be tested in future research. Implications for occupational performance are addressed.

Gal, E., Dyck, M. J., \& Passmore, A. (2010). Relationships between stereotyped movements and sensory processing disorders in children with and without developmental or sensory disorders. American Journal of Occupational Therapy, 64, 453-461. doi: 10.5014/ajot.2010.09075

Stereotyped movements $(S M)$-motor responses that are repetitious; excesSive in rate, frequency, or amplitude; and pursued in an invariant way-are a defining characteristic of autism (American Psychiatric Association, 2000; Schopler, 1995). They are also common among children with an intellectual disability (Rojahn \& Sisson, 1990) or a substantial hearing (Murdoch, 1996) or visual impairment (Tröster, Brambring, \& Beelmann, 1991). In addition to being perceived as inappropriate, odd, and lacking adaptive significance (Baumeister, 1978; Turner, 1999a), a subset of SM is clearly maladaptive because those SM may harm and even threaten the lives of the children who perform them (Matson et al., 1997). Stereotyped self-injurious behaviors are rarely evident among typically developing children but are reported in 52\% of children with a serious visual impairment and 64\% of children with autism (Gal, Dyck, \& Passmore, 2009). Within an occupational context, these behaviors limit the capacity of such children to fully participate in the complex occupational performance demands of life that are affected by both environmental and personal factors (Baum \& Christiansen, 2005).

Among typically developing children, SM have long been regarded as a necessary part of appropriate motor development (Lourie, 1949; Piek, 1995; Thelen, 1979) and are precursors to children's development of postural control (Prechtl, 1993). Among children with a disability, however, the persistence of SM beyond early childhood is often attributed to learning (Durand \& Carr, 1987) or to what are hypothesized to be the core neurocognitive deficits that are thought to 
account for the disorder, such as weak central coherencethat is, the ability to understand context (Frith, 2003) - or impaired executive functioning (Turner, 1997) in the case of children with autism. An alternative view is that children with a range of disabilities also have severe sensory processing disorders (SPD) that cause them to be either overstimulated or understimulated by the environment; SM may help such children maintain an optimal or homeostatic state of stimulation (Gal, Dyck, \& Passmore, 2002; Odberg, 1987).

Children and adults have characteristic ways of processing sensory information. Sensory processing involves the registration and modulation of sensory information as well as the internal organization of sensory input; it results in successful execution of adaptive responses to situational demands and, thus, meaningful engagement in daily occupations (Humphry, 2002). However, for people with SPD, a group of disorders that involve challenges in modulation, integration, organization, and discrimination of sensory input, these differences are extreme and may interfere with daily functioning and emotional-behavioral patterns (Miller, Anzalone, Lane, Cermak, \& Osten, 2007; Miller, Lane, Cermak, Osten, \& Anzalone, 2005). Interference will be greatest with occupations that relate to motor aspects of behavior: body position; motor coordination; fine and gross motor skills; and skills that tap into the interaction between people and objects, such as stabilizing, hand grasping, and manipulating objects (Parham \& Mailloux, 2005; White, Mulligan, Merrill, \& Wright, 2007). Each way of responding to or experiencing sensation may have a corresponding pattern of behavior (Huebner \& Dunn, 2001).

Dysfunctional responsiveness to sensory stimulation is observed in the same disorders in which SM are observed (Miller, Reisman, McIntosh, \& Simon, 2001). Children with autism have been shown to perform more SM when exposed to stimuli to which they are oversensitive (find aversive), to perform fewer SM when exposed to an attractive stimulus, and to perform an intermediate number of SM when exposed to neutral stimuli (Gal et al., 2002). The SM appear to block excessive stimulation (Wehmeyer, 1989) or to increase stimulation in an understimulating environment (Mason, 1991) and thereby help a person to remain within optimal physiological or psychological limits (Fraser \& Broom, 1990).

This account has intuitive appeal in the context of autism in which the extent of SPD is well established and in the context of sensory disorders in which sensory loss entails reduced sensory input. Research with deaf children, however, has suggested that SM are not necessarily present in this group but are observed only among deaf children who have other disabilities, including an intellectual disability (Murdoch, 1996). Nor is it clear that SPD could account for the performance of SM in children with an intellectual disability, among whom SM increase in frequency and severity as the severity of the disability increases (Poustka \& Lisch, 1993). Whether the onethird to two-thirds prevalence of SM in children with an intellectual disability (Rojahn \& Sisson, 1990) can be accounted for by the fact that one third of children with an intellectual disability also have a pervasive developmental disorder (Kraijer, 1997) and, thus, presumptive SPD, is not clear. The case may instead be that the prevalence of SM among children with an intellectual disability simply indicates that those children's use of SM to maintain a homeostatic state reflects their inability to use cognitive resources to cope with new and restricting or frustrating situations (Forehand \& Baumeister, 1971), to initiate alternative activities (Baumeister, MacLean, Kelly, \& Kasari, 1980), or to cope with frustration. If so, an intellectual disability would, like SPD, be a condition that predisposes a child to perform SM to maintain homeostasis and might interact with sensory processing difficulties to increase the frequency or severity of SM when both conditions are present.

\section{Research Aims}

The main aim of this study was to examine relationships between SPD and SM in children with and without developmental or sensory disorders to discover whether SPD accounted for differences in the prevalence and severity of SM across and within groups-that is, to test the hypothesis that group differences in SM are mediated by differences in SPD. A second aim was to assess whether intellectual disability makes an independent contribution to SM, and if so, whether it also interacts with SPD to exacerbate SM.

\section{Method}

\section{Research Design}

To increase the feasibility of the research, we treated intellectual disability as a categorical variable or main factor in a 4 (type of disorder: autism, vision loss, hearing loss, or no sensory disturbance) $\times 2$ (intellectual disability or no intellectual disability) between-groups study. We paired a sample of typically developing children with a sample of children with intellectual disability who had no diagnosed sensory loss or comorbid developmental disorder; these samples constituted the two levels of the No Sensory Disturbance factor. This design allowed us to assess, using analysis of covariance (ANCOVA), whether any between- 
group differences in SM can be accounted for by group differences in SPD or whether additional effects are associated with type of disorder and the presence of an intellectual disability. We used additional regression and correlation analyses to assess relationships between SPD and SM within groups.

\section{Participants}

Participants were recruited after this project had been approved by the Human Research Ethics Committee of Curtin University of Technology (HREC 119/2000). Participants were 221 children (129 boys, 92 girls) 6$13 \mathrm{yr}$ old (mean age $=9.40$, standard deviation $[S D]=$ 1.81) composing five groups: typically developing children $(n=30$, boys $=14$, girls $=16$, mean age $=8.75$, $S D=1.64)$, children with intellectual disabilities $(n=$ 29 , boys $=17$, girls $=12$, mean age $=10.35, S D=2.02$ ), children with visual impairments $(n=50$, boys $=25$, girls $=25$, mean age $=9.02, S D=1.59$ ), children with hearing impairments $(n=56$, boys $=31$, girls $=25$, mean age $=9.29, S D=1.73)$, and children with autism $(n=56$, boys $=42$, girls $=14$, mean age $=9.71$, $S D=1.86$ ). All participants were living with their families and were attending a state school, a segregated school, or a semi-inclusive school in the Haifa metropolitan region of northern Israel. Children with a developmental or sensory disorder had been diagnosed by a physician or a psychologist from medical developmental services.

Before recruitment of all children into the study, school principals gave their consent to take part in the study, as did the participants' teachers, who gave their informed consent to participate in interviews about the children in the study sample.

Typically developing children were a convenience sample of second to fourth graders recruited from a state school. Children with an intellectual disability had been diagnosed by psychological services according to Diagnostic and Statistical Manual of Mental Disorders (4th ed., text rev., or DSM-IV-TR; American Psychiatric Association, 2000) criteria, and all had a measured IQ $<70$. The educational system had also declared them as having a mild or moderate intellectual handicap and as being in need of special education. These participants were recruited from three special education segregated schools, that is, schools that educated only children with an intellectual disability.

Children with visual impairments included two subgroups: those who had typical intelligence (IQ $\geq 70$; $n=25)$ and those who also had an intellectual disability (IQ $<70 ; n=25)$. All the children had been defined by medical services as legally blind or having visual loss and, as a result, were eligible for special education support. They were recruited from special school classes designed for them. Children with hearing impairments included the same subgroups: those who had typical intelligence (IQ $\geq 70 ; n=34$ ) and those with an intellectual disability (IQ $<70 ; n=22$ ). All of these children had been defined by medical services as requiring hearing aids and as eligible for special educational support. They were recruited from special school classes designed for them.

Children with autism were diagnosed on the basis of $D S M-I V-T R$ criteria and by the Childhood Autism Rating Scale (Schopler, Reichler, \& Renner, 1998). Half $(n=28)$ of the children had typical intelligence, and half had an intellectual disability. All the children were defined by psychological services as eligible for special education in a school for children with autism spectrum disorders and were recruited from two such special education schools.

For all samples, children were excluded if they had been diagnosed with other specific syndromes strongly associated with specific repetitive movements, including Lesch Nyhan syndrome, Cornelia de Lange syndrome, Riley-Day familial dysautonomia, fragile X syndrome, and Rett syndrome. These syndromes are associated with an abnormal metabolism or a specific X-linked gene, and children with these syndromes have known sensory abnormalities that differentiate them from other populations with intellectual disabilities. We also excluded children with tardive dyskinesia. In addition, the group with intellectual disability did not include children with a diagnosed sensory loss or impairment.

Statistical tests indicate that groups differed in age $(F[4,216]=4.14, p=.003)$ and $\operatorname{sex}\left(\chi^{2}[4,221]=\right.$ 9.71, $p=.045)$. Post hoc tests indicated that children in the typically developing group were younger than those in the groups with intellectual disability and autism; children in the groups with intellectual disability and autism were also older than those in the groups with visual and hearing impairment. Girls were overrepresented in the group with intellectual disability and boys were overrepresented in the group with autism; the latter result is consistent with gender differences in the prevalence of autism.

\section{Instruments}

The Short Sensory Profile (SSP; McIntosh, Miller, Shyu \& Dunn, 1999) is a caregiver Likert-style rating scale that reports behavioral sensory processing difficulties in children ages 3-10 yr; however, in the context of people with disabilities, the profile is used with people $\leq 21 \mathrm{yr}$ old 
(Dunn, 1999). The SSP was designed for screening and research use and includes 38 items that demonstrate the highest discriminative power of atypical sensory processing among the 125 items from the long version, the Sensory Profile (Dunn, 1999). The SSP includes seven sections: tactile sensitivity, taste or smell sensitivity, movement sensitivity, underresponsive or seeks sensation, auditory filtering, low energy or weak, and visual or auditory sensitivity. Item scores within each section are summed to yield a section score, and section scores are summed to yield a total summary score. Section scores are categorized within three categories: typical performance, probable difference, and definite difference. The categories are based on a classification system derived from norms, that is, the range of scores of children without disabilities as they performed on each subtest. This system allows for the construction of individual profiles that compare each child's performance to normative performance. Internal consistency of the sections within the scale ranged from .70 to .90 . Internal validity correlations for the sections ranged from .25 to .76 and were all significant at $p<.01$ (Dunn, 1999).

The SSP has been found to identify sensory difficulties among children with sensory modulation difficulties (Miller et al., 2001), autism and fragile X syndrome (Miller et al., 2001; Rogers, Hepburn, \& Wehner, 2003), and attention deficit disorder (Mangeot et al., 2001). Given its short administration time $(10 \mathrm{~min})$ and value in screening for atypical sensory processing, the SSP is recommended for research protocols (Dunn, 1999). We treated both section scores and the SSP total score, which is the most sensitive indicator of sensory dysfunction, as dependent variables in this study. The SSP isolates sensory processing that is less confounded by items overlapping with the diagnostic features of autism (Tomchek \& Dunn, 2007), and it is therefore appropriate for this study.

In this study, we chose special education teachers to be the designated reporters rather than caregivers because in the targeted settings, children were taught in small classes (6-8 children with two teachers), over long hours, and so their teachers knew them well and were able to fully describe their behaviors.

The Stereotyped and Self-Injurious Movement Interview (SSIMI; Turner, 1999b), an adaptation of the Repetitive Behaviors Interview (Turner, 1999b), is a $32-$ item clinician-administered questionnaire designed to assess stereotyped body movements, manipulation of objects, and self-injurious behavior (Gal et al., 2002, 2009). The SSIMI assesses how many different SM a child performs, the frequency with which each form of SM is performed (e.g., once or twice per week, $\geq 30$ times per week), the duration of each performance (e.g., $<60 \mathrm{~s},>30 \mathrm{~min}$ ), and the intensity with which SM are performed (e.g., two or three movements per $10 \mathrm{~s}, \geq 10$ movements per $10 \mathrm{~s}$ ). The SSIMI is internally consistent $(\alpha=.79)$ and appears to be sensitive to group differences in the frequency or severity of SM (Gal et al., 2009). Because research has shown that indexes of SM frequency, intensity, and duration are strongly correlated with SM prevalence (how many different SM a child performs; Gal et al., 2009), we report results only for the prevalence index.

\section{Procedures}

The SSP and SSIMI were administered to the participants' teachers by Eynat Gal, an experienced and doctorally qualified occupational therapist who developed the SSIMI, as a face-to-face interview in their home schools. Interviews lasted approximately $60 \mathrm{~min}$ per child.

\section{Data Analysis}

We conducted several analyses. First, descriptive statistics (means and SDs) were used to describe the SM and SSP scores within each sample. Second, we calculated Pearson correlation coefficients to assess the strength of any linear relationship between SSP scores and SM within and across samples. Third, we conducted a series of stepwise multiple regression analyses to discover which linear combination of SSP section scores best predicted SM within and across samples. Finally, to define whether group differences in sensory processing anomalies accounted for differences in SM, we conducted an analysis of variance (ANOVA) with disorder type and intellectual disability as the main factors and SSP summary scores as the covariate.

\section{Results}

Descriptive statistics (means and $S D s$ ) for the prevalence of SM and the SSP summary scores are reported in Table 1. The prevalence of SM across disorders shows marked differences, and within a disorder category, more SM are always present in the subgroups with intellectual disability. The identical pattern is evident in SSP scores, with lower scores indicating greater sensory differences, always evident in the subgroups with intellectual disability.

We calculated Pearson correlation coefficients to assess the strength of any linear relationship between SPD and SM within and across samples. The results (see Table 2) indicate significant and sometimes strong relationships between the SSP summary score and SM in each sample and in the combined sample and between each SSP section score and SM in at least one sample. Correlations tended to be strongest in the typically developing sample 
Table 1. Mean Number (and Standard Deviation [SD]) of Stereotyped Movements and Short Sensory Profile Summary Scores, by Sample

\begin{tabular}{|c|c|c|c|c|}
\hline \multirow[b]{2}{*}{ Sample and IQ Status } & \multicolumn{2}{|c|}{$\begin{array}{c}\text { Stereotyped } \\
\text { Movement }\end{array}$} & \multicolumn{2}{|c|}{$\begin{array}{l}\text { Short Sensory } \\
\text { Profile Score }\end{array}$} \\
\hline & Mean & $S D$ & Mean & $S D$ \\
\hline \multicolumn{5}{|l|}{ No sensory disorder } \\
\hline$\geq 70$ & 0.50 & 0.73 & 184.13 & 8.49 \\
\hline$<70$ & 1.86 & 2.13 & 163.97 & 20.75 \\
\hline \multicolumn{5}{|l|}{ Autism } \\
\hline$\geq 70$ & 5.21 & 2.79 & 132.21 & 21.66 \\
\hline$<70$ & 8.92 & 3.38 & 121.43 & 18.19 \\
\hline \multicolumn{5}{|l|}{ Vision loss } \\
\hline$\geq 70$ & 2.48 & 2.46 & 157.04 & 17.31 \\
\hline$<70$ & 4.88 & 2.08 & 138.44 & 11.43 \\
\hline \multicolumn{5}{|l|}{ Hearing loss } \\
\hline$\geq 70$ & 1.38 & 1.72 & 165.26 & 19.66 \\
\hline$<70$ & 3.77 & 2.56 & 155.27 & 19.53 \\
\hline
\end{tabular}

Note. For the Short Sensory Profile, lower scores indicate greater sensory processing problems.

and weakest in the sample with autism; which section score is most strongly related to SM differs across samples (e.g., the best predictor of SM in the typically developing group was low energy or weak, the best predictor in the group with intellectual disability was visual-auditory, and the best predictor in the group with hearing impairment was underresponsive).

Multiple regression analyses indicated that for the combined sample, the combination of underresponsive, taste or smell, tactile, and visual-auditory section scores accounted for $>50 \%$ of variance in SM (adjusted $R^{2}=.53$, $F[4,216]=65.12, p<.001)$. For individual samples, results were as follows: typically developing sample, weak and tactile section scores, adjusted $R^{2}=.51, F(2,27)=$ $14.37, p<.001$; sample with intellectual disability, visualauditory section scores adjusted $R^{2}=.52, F(1,27)=$ 29.54, $p<.001$; sample with autism, underresponsive scores, adjusted $R^{2}=.17, F(1,54)=12.76, p=.001$; sample with visual impairment, tactile section scores, adjusted $R^{2}=.17, F(1,48)=11.54, p=.001$; and sample with hearing impairment, underresponsive and tactile section scores, adjusted $R^{2}=.40, F(2,53)=17.66, p<.001$.
Finally, we conducted a 4 (disorder type) $\times 2$ (intellectual disability category) ANOVA with SSP summary scores as the covariate. The analysis indicated that the model accounted for $60 \%$ of variability in SM prevalence $\left(F[8,212]=43.74, p<.001, \varepsilon^{2}=.623\right)$. We observed a significant effect for the covariate $(F[1,212]=33.47, p<$ $\left..001, \varepsilon^{2}=.136\right)$, for disorder type $(F[3,212]=15.26, p<$ $\left..001, \varepsilon^{2}=.178\right)$, for intellectual disability category $(F[1$, $\left.212]=29.97, p<.001, \varepsilon^{2}=.124\right)$, and for the Disorder Type $\times$ Intellectual Disability Category interaction $(F[3$, $\left.212]=4.05, p<.01, \varepsilon^{2}=.054\right)$. Estimated marginal means for the interaction, the predicted mean SM score for each group when the covariate is taken into account (see Table 3), suggest that group differences in sensory processing anomalies account for differences in SM among the typically developing, intellectual disability, hearing impairment higher IQ, and possibly the visual impairment higher IQ samples. The results reported in Table 3 suggest that autism makes a separate contribution to SM prevalence and lower IQ interacts with autism and hearing and visual impairment to increase SM prevalence. When group differences related to sensory processing are taken into account, children with autism who do not have an intellectual disability perform more SM than children with any other combination of disabilities, and children with any one disability, including an intellectual disability, hearing impairment, or vision impairment, do not differ substantially from typically developing children. And even though children with an intellectual disability do not have increased SM when sensory processing is taken into account, comorbidity of an intellectual disability with autism, hearing impairment, and visual impairment substantially increases the prevalence of SM.

\section{Discussion}

The main aim of this study was to discover whether SPD, as measured by sensory difference scores from the SSP, account for within- and between-group differences in the prevalence of SM. The results indicate that they do. A second aim was to assess whether an intellectual disability

Table 2. Pearson Correlation Coefficients Between Number of Different Stereotyped Movements and Short Sensory Profile Summary and Section Scores, by Sample

\begin{tabular}{|c|c|c|c|c|c|c|c|c|}
\hline Sample & Summary & Auditory & Movement & Tactile & Taste-Smell & Underresponsive & Visual-Auditory & Weak \\
\hline Combined & $-.69^{\star \star}$ & $-.53^{\star \star}$ & $-.22^{\star \star}$ & $-.55^{\star \star}$ & $-.40^{\star \star}$ & $-.62^{\star \star}$ & $-.45^{\star \star}$ & $-.25^{\star \star}$ \\
\hline Typical & $-.68^{\star \star}$ & $-.55^{\star \star}$ & $-.46^{\star \star}$ & $-.39^{\star \star}$ & $-.49^{\star \star}$ & $-.46^{\star \star}$ & .23 & $-.64^{\star \star}$ \\
\hline Intellectual disability & $-.68^{\star *}$ & $-.39^{\star}$ & .019 & -.22 & -.30 & $-.41^{\star}$ & $-.72^{\star \star}$ & -.36 \\
\hline Autism & $-.28^{\star}$ & -.22 & .17 & -.11 & -.12 & $-.43^{\star *}$ & $-.31^{\star}$ & .11 \\
\hline Vision loss & $-.50 \star \star$ & $-.29^{\star}$ & -.27 & $-.44^{\star \star}$ & -.14 & $-.36^{\star}$ & .12 & $-.34^{\star}$ \\
\hline Hearing loss & $-.55^{\star \star}$ & $-.52^{\star \star}$ & -.24 & $-.50 * \star$ & -.09 & $-.57^{\star \star}$ & $-.37^{\star \star}$ & -.03 \\
\hline
\end{tabular}

$* p<.05$, two tailed. $* * p<.01$, two tailed. 
Table 3. Estimated Marginal Means for the Interaction Between Disorder Type and IQ Status, Covarying Short Sensory Profile Summary Scores

\begin{tabular}{lcc}
\hline QQ Status & Mean & Standard Error \\
\hline $\begin{array}{l}\text { No sensory disorder } \\
\geq 70\end{array}$ & 2.01 & \\
$\quad<70$ & 2.39 & 0.47 \\
Autism & & 0.41 \\
$\geq 70$ & 4.21 & \\
$<70$ & 7.40 & 0.44 \\
Vision loss & & 0.48 \\
$\geq 70$ & 2.67 & \\
$<70$ & 4.17 & 0.43 \\
Hearing loss & & 0.45 \\
$\geq 70$ & 1.97 & \\
$<70$ & 3.88 & 0.38 \\
\hline
\end{tabular}

makes an independent contribution to SM and whether it interacts with sensory-processing differences to exacerbate SM. The results suggest that an intellectual disability does not contribute directly to SM but interacts with sensory impairment and autism to increase the prevalence of SM. These results are consistent with the hypothesis that SM are an adaptive form of behavior that enable a person with SPD to cope with sensory over- and underresponsivity.

A consistent body of evidence has indicated that atypical sensory processing is a central feature of autism (Cesaroni \& Garber, 1991; Dawson \& Watling, 2000; Iarocci \& McDonald, 2006; Rogers \& Ozonoff, 2005), but its relationship to $\mathrm{SM}$ in people with and without autism had not been established. What our results imply is that disorders vary according to what set of sensoryprocessing anomalies are affected or are the main source of overstimulation or understimulation. Although underresponsiveness was associated with SM in all samples, it was the best predictor of SM only in the groups with autism or hearing impairment (Rogers \& Ozonoff, 2005); in other groups, anomalies in the low energy or weak, visual-auditory, or tactile sections were what best predicted SM.

Our results indicate that atypical sensory processing is strongly related to SM not only in children with autism but also in children with intellectual disability or hearing or vision loss or who are typically developing. Indeed, correlations between SSP section scores and SM are consistently stronger in a typically developing child sample than in other samples and account for $50 \%$ of the variability in SM among typically developing children. This finding is important because it suggests that atypical sensory processing, however caused, not atypical processing resulting from autism or some other specific disorder, contributes to increases in SM.
The finding that SPD are associated with SM in all samples allows us to conclude that an intellectual disability is unlikely to be a direct contributor to SM. Although the prevalence of SM is significantly greater in all samples with an intellectual disability, so too is the severity of SPD, and across samples, a rank ordering of SM severity is matched by the rank ordering of SPD severity. As the analysis of covariance showed, in the absence of sensory impairment or a diagnosis of autism, children with an intellectual disability do not differ from typically developing children (or from people with no intellectual disability or with hearing and, perhaps, visual impairments) when the severity of SPD is covaried. Because we did not assess participants' intelligence, we cannot assess how directly SPD covaries with IQ, but we can speculate that the processes responsible for an intellectual disability are also those processes responsible for more severe SPD in people with intellectual disability and that these SPD are responsible for the increased prevalence of SM in these groups.

Where intellectual disability appears to exert its influence is in its interaction with sensory impairment or autism to exacerbate the severity of SM. As shown in Table 3 , the estimated severity of SM for each sensory disorder is 1.5 to 2 times as great when a child also has an intellectual disability. These increases in SM are disproportionate to children's sensory processing problems, at least as measured by the SSP, and imply a qualitative change in the disabling consequences of SPD in children with multiple disorders. Such a qualitative change might reflect the role of dynamic processes, especially the disruption of the reciprocal and mutually beneficial cognitive processes that occur during typical development (van der Maas et al., 2006). Instead of sensory processing's facilitating intellectual and motor development and vice versa, in people with intellectual and sensory disorders processing of any kind may interfere with other systems, causing disequilibrium within the dynamic system (Glencross, 1995).

This kind of disequilibrium is illustrated by how the sample with autism was distinguished from all other samples. In this group, both SPD and SM were most prevalent and severe, such that high-functioning children with autism had more SM than low-functioning children in any other group (see Table 3). In this sample, SM were less well predicted by SPD than in any other sample, possibly because the character of autism entails such aberrant sensory processing that scales such as the SSP cannot adequately assess individual differences within a sample with autism. Increasing evidence indicates that not only sensory integration processes are disrupted in autism. Rather, at all ability levels, whatever a child with 
autism attains on any task results from atypical information processing (Dyck, Piek, Hay, Smith, \& Hallmayer, 2006), so that even when typical behavioral output is achieved, it is achieved by atypical physiological processing (Belmonte \& Yurgelun-Todd, 2003). According to Frith and Happé (1994; Happé \& Frith, 2006), atypical processing reflects an imbalance in integration of information at different levels of integrative complexity. Sensory integration problems represent one facet of a broader problem integrating information, which may predispose a child to develop a range of peculiar, occasionally maladaptive coping strategies to compensate for the disequilibrium that has resulted from the inability to integrate information. When a child has both sensory impairment and an intellectual disability, the interaction between disabilities somewhat mimics the aberrant processing of people with autism.

The results of this study challenge us to consider the complex nature of sensory processing and SM. Attention to the environmental context and resultant sensory stimuli may be of great importance in working with children with autism and other developmental disabilities.

\section{Conclusions, Limitations, and Future Research}

Moderate to strong relationships exist between SPD and SM in children with a sensory impairment, an intellectual disability, or autism or who are typically developing. These relationships suggest that future research needs to assess whether these phenomena have a functional and statistical relationship (Gal et al., 2002). Similarly, a strong relationship exists between the severity of SPD and SM across disorders, and between-group differences in sensory processing problems account for differences in the prevalence of SM between typical children, children with an intellectual disability, and children with sensory loss who do not have an intellectual disability. The severity of SPD, not sensory impairment or intellectual disability per se, appears to determine the prevalence of SM. These results suggest that functional connections between these phenomena need to be assessed in future research. The SM of children with autism and children with both sensory impairment and an intellectual impairment are not well accounted for simply by SPD but may reflect a more generalized problem integrating information, which may be an additional source of disequilibrium necessitating additional compensatory behavior. These conclusions need to be tempered by several limitations of this study, including no individual assessment of intelligence and our reliance on a single rating form to assess SPD. Also, our reliance on teachers' ratings limits the generalizability of the results to educational settings. Future research should undertake analyses of the relationship between SM, sensory processing, and occupational performance outcomes in specific dimensions and contexts, especially noneducational ones. At the applied level, this study may suggest that clinicians use people's behaviors and, specifically, their SM as indicators for their sensory systems and extend the focus of intervention from a behaviorally based intervention to one that includes both addressing the individual's sensory differences through direct intervention and adapting the sensory environment.

\section{References}

American Psychiatric Association. (2000). Diagnostic and statistical manual of mental disorders (4th ed., text rev.). Washington, DC: Author.

Baum, C., \& Christiansen, C. (2005). Person-environmentoccupational performance: An occupation-based framework for practice. In C. Christiansen \& C. Baum (Eds.), Occupational therapy: Performance, participation and wellbeing (pp. 242-267). Thorofare, NJ: Slack.

Baumeister, A. A. (1978). Origins and control of stereotyped movements. In C. E. Meyers (Ed.), Quality of life in severely and profoundly mentally retarded people: Research foundations for improvement (Monograph No. 3). Washington, DC: American Association for Mental Deficiency.

Baumeister, A. A., MacLean, W. E., Jr., Kelly, J., \& Kasari, C. (1980). Observational studies of retarded children with multiple stereotyped movements. Journal of Abnormal Child Psychology, 8, 501-521. doi:10.1007/BF00916503

Belmonte, M. K., \& Yurgelun-Todd, D. A. (2003). Functional anatomy of impaired selective attention and compensatory processing in autism. Cognitive Brain Research, 17, 651-664. doi:10.1016/S0926-6410(03)00189-7

Cesaroni, L., \& Garber, M. (1991). Exploring the experience of autism through firsthand accounts. Journal of $A u$ tism and Developmental Disorders, 21, 303-313. doi:10.1007/ BF02207327

Dawson, G., \& Watling, R. (2000). Interventions to facilitate auditory, visual, and motor integration in autism: A review of the evidence. Journal of Autism and Developmental Disorders, 30, 415-421. doi:10.1023/A:1005547422749

Dunn, W. (1999). The Sensory Profile: User's manual. San Antonio, TX: Psychological Corporation.

Durand, V. M., \& Carr, E. G. (1987). Social influences on "self-stimulatory" behavior: Analysis and treatment application. Journal of Applied Behavior Analysis, 20, 119-132. doi:10.1901/jaba.1987.20-119

Dyck, M. J., Piek, J. P., Hay, D., Smith, L., \& Hallmayer, J. (2006). Are abilities abnormally interdependent in children with autism? Journal of Clinical Child and Adolescent Psychology, 35, 20-33. doi:10.1207/s15374424jccp3501_3

Forehand, R., \& Baumeister, A. A. (1971). Stereotyped body rocking as a function of situation, IQ and time. Journal of 
Clinical Psychology, 27, 324-326. doi:10.1002/1097-4679 (197107)27:3<324::AID-JCLP2270270307>3.0.CO;2-O

Fraser, A. F., \& Broom, D. M. (1990). Farm animal behaviour and welfare. London: Bailliere Tindall.

Frith, U. (2003). Autism: Explaining the enigma. Malden, England: Blackwell.

Frith, U., \& Happé, F. (1994). Autism: Beyond "theory of mind." Cognition, 50, 115-132. doi:10.1016/0010-0277(94)90024-8

Gal, E., Dyck, M., \& Passmore, A. (2002). Sensory differences and stereotyped movements in children with autism. Behaviour Change, 19, 207-219. doi:10.1375/bech.19.4.207

Gal, E., Dyck, M. J., \& Passmore, A. (2009). The relationship between stereotyped movements and self-injurious behavior in children with developmental or sensory disabilities. Research in Developmental Disabilities, 30, 342-352.

Glencross, D. J. (1995). Motor control and sensory-motor integration. In D. J. Glencross \& J. P. Piek (Eds.), Motor control and sensory motor integration (pp. 1-10). Amsterdam: North Holland/Elsevier Science.

Happé, F., \& Frith, U. (2006). The weak central coherence account: Detail-focused cognitive style in autism spectrum disorders. Journal of Autism and Developmental Disorders, 36, 5-25. doi:10.1007/s10803-005-0039-0

Huebner, R. A., \& Dunn, W. (2001). Understanding autism and the sensorimotor findings in autism: Introduction and basic concepts. In R. A. Huebner (Ed.), Autism: A sensorimotor approach to management (pp. 1-35). Frederick, MD: Aspen.

Humphry, R. (2002). Young children's occupations: Explicating the dynamics of developmental processes. American Journal of Occupational Therapy, 56, 171-179.

Iarocci, G., \& McDonald, J. (2006). Sensory integration and the perceptual experience of persons with autism. Journal of Autism and Developmental Disorders, 36, 77-90. doi: 10.1007/s10803-005-0044-3

Kraijer, D. W. (1997). Autism and autistic-like conditions in mental retardation. Lisse, The Netherlands: Swets \& Zeitlinger.

Lourie, R. S. (1949). The role of rhythmic patterns in childhood. American Journal of Psychiatry, 103, 653-660.

Mangeot, S. D., Miller, L. J., McIntosh, D. N., McGrath-Clarke, J., Simon, J., Hagerman, R. J., et al. (2001). Sensory modulation dysfunction in children with attention deficit hyperactivity disorder. Developmental Medicine and Child Neurology, 43, 399-406. doi:10.1017/S0012162201000743

Mason, G. J. (1991). Stereotypies: A critical review. Animal Behaviour, 41, 1015-1037. doi:10.1016/S0003-3472(05) 80640-2

Matson, J. L., Hamilton, M., Duncan, D., Bamburg, J., Smiroldo, B., Anderson, S., et al. (1997). Characteristics of stereotypic movement disorder and self-injurious behavior assessed with the Diagnostic Assessment for the Severely Handicapped (DASH-II). Research in Developmental Disabilities, 18, 457-469. doi:10.1016/S0891-4222(97)00022-X

McIntosh, D. N., Miller, L. J., Shyu, V., \& Dunn, W. (1999). Short Sensory Profile. San Antonio, TX: Psychological Corporation.

Miller, L. J., Anzalone, M. E., Lane, S. J., Cermak, S. A., \& Osten, E. T. (2007). Concept evolution in sensory inte- gration: A proposed nosology for diagnosis. American Journal of Occupational Therapy, 61, 135-140.

Miller, L. J., Lane, S., Cermak, S. A., Osten, E., \& Anzalone, M. (2005). Regulatory-sensory processing disorders in children. In S. I. Greenspan \& S. Wieder (Eds.), Diagnostic manual for infancy and early childhood: Mental health, developmental, regulatory-sensory processing and language disorders and learning challenges (ICDL-DMIC; pp. 73-112). Bethesda, MD: Interdisciplinary Council on Developmental and Learning Disorders.

Miller, L. J., Reisman, J. E., McIntosh, D. N., \& Simon, J. (2001). An ecological model of sensory modulation: Performance of children with fragile $\mathrm{X}$ syndrome, autistic disorder, attention-deficit/hyperactivity disorder, and sensory modulation dysfunction. In S. S. Roley, E. I. Blanche, \& R. C. Schaff (Eds.), Understanding the nature of sensory integration with diverse populations (pp. 75-88). Tucson, AZ: Therapy Skill Builders.

Murdoch, H. (1996). Stereotyped behaviors in deaf and hard of hearing children. American Annals of the Deaf, 141, 379-386.

Odberg, F. (1987). Behavioural responses to stress in farm animals. In P. W. M. V. Adrichem \& P. R. Weipkema (Eds.), The biology of stress in farm animals: An integrated approach (pp. 135-149). Dordrecht, The Netherlands: Martinus Nijhoff.

Parham, L. D., \& Mailloux, Z. (2005). Sensory integration. In J. Case-Smith, A. Allen, \& P. N. Pratt (Eds.), Occupational therapy for children. (5th ed., pp. 356-411). St. Louis, MO: Mosby.

Piek, J. P. (1995). The contribution of spontaneous movements in the acquisition of motor coordination in infants. In D. J. Glencross \& J. P. Piek (Eds.), Motor control and sensory motor integration (pp. 199-230). Amsterdam: Elsevier.

Poustka, F., \& Lisch, S. (1993). Autistic behaviour domains and their relation to self-injurious behaviour. Acta Paedopsychiatrica, 56, 69-73.

Prechtl, H. F. R. (1993). Principles of early motor development in the human. In A. F. Kalverboer, B. Hopkins, \& R. Geuze (Eds.), Motor development in early and later childhood: Longitudinal approaches (pp. 35-50). Cambridge, England: Cambridge University Press.

Rogers, S. J., Hepburn, S. L., \& Wehner, E. (2003). Parent reports of sensory symptoms in toddlers with autism and those with other developmental disorders. Journal of $A u$ tism and Developmental Disorders, 33, 631-642. doi:10.1023/ B: JADD.0000006000.38991.a7

Rogers, S. J., \& Ozonoff, S. (2005). Annotation: What do we know about sensory dysfunction in autism? A critical review of the empirical evidence. Journal of Child Psychology and Psychiatry and Allied Disciplines, 46, 1255-1268. doi: 10.1111/j.1469-7610.2005.01431.x

Rojahn, J., \& Sisson, A. L. (1990). Stereotyped behavior. In J. L. Matson (Ed.), Handbook of behavior modification with the mentally retarded (2nd ed.; pp. 181-223). New York: Plenum Press.

Schopler, E. (1995). Parent survival manual. New York: Plenum Press. 
Schopler, E., Reichler, R., \& Renner, B. (1998). The Childhood Autism Rating Scale (CARS). Los Angeles: Western Psychological Services.

Thelen, E. (1979). Rhythmical stereotypies in normal human infants. Animal Behaviour, 27, 699-715. doi:10.1016/ 0003-3472(79)90006-X

Tomchek, S. D., \& Dunn, W. (2007). Sensory processing in children with and without autism: A comparative study using the Short Sensory Profile. American Journal of $\mathrm{Oc}^{-}$ cupational Therapy, 61, 190-200.

Tröster, H., Brambring, M., \& Beelmann, A. (1991). Prevalence and situational causes of stereotyped behaviors in blind infants and preschoolers. Journal of $A b$ normal Child Psychology, 19, 569-590. doi:10.1007/ BF00925821

Turner, M. A. (1997). Toward an executive dysfunction account of repetitive behaviour in autism. In J. Russell (Ed.), Autism as an executive disorder (pp. 57-100). Oxford, England: Oxford University Press.
Turner, M. A. (1999a). Annotation: Repetitive behaviour in autism: a review of psychological research. Journal of Child Psychology and Psychiatry, and Allied Disciplines, 40, 839-849. doi:10.1111/1469-7610.00502

Turner, M. A. (1999b). Repetitive behaviours interview. Unpublished interview.

van der Maas, H. L., Dolan, C. V., Grasman, R. P., Wicherts, J. M., Huizenga, H. M., \& Raijmakers, M. E. (2006). A dynamical model of general intelligence: The positive manifold of intelligence by mutualism. Psychological Review, 113, 842-861. doi:10.1037/0033-295X.113.4.842

Wehmeyer, M. L. (1989). Repetitive motor behaviors in young children at-risk for severe developmental delay: Implications for pathological stereotypes in mental retardation. Unpublished doctoral dissertation, University of Texas, Dallas.

White, B. P., Mulligan, S., Merrill, K., \& Wright, J. (2007). An examination of the relationships between motor and process skills and scores on the sensory profile. American Journal of Occupational Therapy, 61, 154-160. 